\title{
Alternative and Online Assessment in the Context of Outcome Based Education: A Practical Guide
}

\author{
Rohana Sapawi*1, Azzahrah Anuar ${ }^{2}$, Rafeah Wahi ${ }^{3}$, Nur Tahirah Razali ${ }^{4}$, Mohd Hafizan Hashim ${ }^{5}$ \\ 1,4,5Center for Development and Management Academic, Universiti Malaysia Sarawak, \\ Jalan Datuk Mohammad Musa, Kota Samarahan, Malaysia \\ ${ }^{1,4}$ Faculty of Engineering, Universiti Malaysia Sarawak,JalanDatuk Mohammad Musa, \\ Kota Samarahan, Malaysia \\ ${ }^{2,5}$ Faculty of Cognitive Science and Human Development, Universiti Malaysia Sarawak, \\ Jalan Datuk Mohammad Musa, Kota Samarahan,Malaysia \\ ${ }^{3}$ Faculty of Resource Science and Technology, Universiti Malaysia Sarawak, \\ Jalan Datuk Mohammad Musa, Kota Samarahan,Malaysia \\ Corresponding Author: ${ }^{1 *}$ srohana@ unimas.my
}

Article History: Received: 10 November 2020; Revised: 12 January 2021; Accepted: 27 January 2021; Published online: 05 April 2021

\begin{abstract}
Alternative assessment measures the learner's ability and proficiency in performing complex tasks that are related to the intended learning outcomes and relies on direct measures of target skills in a specific knowledge or skill-domain. Meanwhile, online assessment is an assessment conducted in an online environment on a fully automated platform. Both types of assessments are getting a substantial attention worldwide due to their many advantages. However, several factors must be taken into consideration in implementing the alternative and online assessment in an outcome- based education (OBE) system. Thus, this paper provides a practical guide to alternative and online assessment in the context of OBE including the constructive alignment, student learning time and development of assessment rubrics. Other considerations are also discussed, namely the validity and reliability of the alternative and online assessment, and deterring plagiarism and cheating.

Keywords: Alternative assessment, Online assessment, Higher education, Outcome-based education
\end{abstract}

\section{Introduction}

Assessment is as an integral part of the teaching and learning process that captures a learner's progress through active participation of the learner himself; whether the goals of learning are being met or not. The traditional or conventional practice for evaluating outcomes is an assessment of learning (Ewin\& Mohamed, 2015). However, new perspective proposes that assessment should not only include assessment of learning, but also to include both assessment for learning and assessment as learning.

Hence, a holistic assessment can be viewed from three different perspectives: assessment of learning, assessment for learning, and assessment as learning. Assessment of learning is potentially summative and its purpose is to ascertain what the learners know in relation to curriculum outcomes. It is for instructors to make infallible and reasonable decisions (Race et. al., 2005, p. 17). Meanwhile, assessment for learning regards learners as unique individuals who learn in idiosyncratic ways. This kind of assessment provides feedback to learners and offers a helping hand to instructors to benefit from the information available to streamline instruction. Assessment for learning offers a number of opportunities for learners to develop their own skills by making evaluations about their own performances. Finally, assessment as learning is a way of intensifying learners' metacognition. It has an eye on the role of each learner as an active connector between assessment and learning. The learners are critical assessors as they make sense of information provided and consume it for learning new concepts. It is not possible unless the learners make adjustments from what they have monitored. This process is accompanied by a critical and reflective analysis of their ownlearning.

As a reciprocal process of teaching and learning, assessment deals with what is taught and what is learned (Kellough\&Kellough, 1999) throughout the academic years. Assessment should be meticulously designed to measure both knowledge and skills in order to enhance the learner's learning. As proposed by Nasab (2015), a high quality and well-designed assessment should "engage learners with their own learning, setting aside the obvious advantages of its being a tool of measurement" (p. 168) as well as provide meaningful learning experience to the learners. Assessment, hence, should be seen as a central to the learning experience that determines how much time should be allocated on what is considered important-for both learners and instructors. Assessment should prepare learners to deal with ambiguous real-life problems that requires higherorder thinkingabilities. 